\title{
A violência como prática civilizatória. Relações entre indígenas, missionários, militares e fazendeiros nos aldeamentos capuchinhos do século XIX no sul da província de Mato Grosso
}

Violence as a civilizing practice. Relations among indigenous peoples, missionaries, soldiers and farmers in nineteenth century Capuchin villages in the southern province of Mato Grosso

\section{Pablo Antunha Barbosa}

\section{(2) OpenEdition}

1 Journals

\section{Edición electrónica}

URL: http://journals.openedition.org/corpusarchivos/409

DOI: $10.4000 /$ corpusarchivos.409

ISSN: 1853-8037

\section{Editor}

Diego Escolar

Referencia electrónica

Pablo Antunha Barbosa, «A violência como prática civilizatória. Relações entre indígenas, missionários, militares e fazendeiros nos aldeamentos capuchinhos do século XIX no sul da província de Mato Grosso », Corpus [En línea], Vol 3, No 1 | 2013, Publicado el 15 junio 2013, consultado el 01 mayo 2019. URL : http://journals.openedition.org/corpusarchivos/409 ; DOI : 10.4000/ corpusarchivos.409

Este documento fue generado automáticamente el 1 mayo 2019. 


\section{A violência como prática civilizatória. Relações entre indígenas, missionários, militares e fazendeiros nos aldeamentos capuchinhos do século XIX no sul da província de Mato Grosso}

Violence as a civilizing practice. Relations among indigenous peoples, missionaries, soldiers and farmers in nineteenth century Capuchin villages in the southern province of Mato Grosso

Pablo Antunha Barbosa

\section{NOTA DEL EDITOR}

Fecha de recepción del original: 10-04-2013

Fecha de aceptación para publicación: 14-05-2013

O documento que ora se publica encontra-se conservado no Arquivo Público do Estado de Mato Grosso (APMT) localizado na cidade de Cuiabá. Trata-se, pormenorizadamente, de uma série de acusações perpetradas contra supostos atos de violência que o capuchinho italiano, frei Ângelo de Caramonico, então diretor-missionário da Aldeia de Nossa Senhora do Bom Conselho, localizada na freguesia de Albuquerque, teria cometido contra o índio Manoel José no ano de 1862. Apesar do documento não estar datado e nem mesmo assinado, não é difícil contextualizá-lo de forma bastante clara a partir de uma série de outros documentos também encontrados no APMT, e que orbitam em torno deste mesmo dossiê. Do ponto de vista analítico, o fato do documento não estar assinado e datado é até 
interessante, visto que ao buscar reconstruir seu contexto histórico de produção, torna-se fundamental um questionamento sobre as lógicas que dão sentido às diferentes posições apresentadas pelos atores que estão envolvidos nesse jogo de acusações.

Resumidamente, pode-se dizer que na noite do dia 9 de Agosto de 1862, frei Ângelo de Caramonico mandou uma pequena escolta militar até a sede do engenho Recreio, de propriedade do Capitão Manoel José de Carvalho, localizada a meia légua de distância da Aldeia de Nossa Senhora do Bom Conselho. O objetivo mais imediato da diligência repressiva era a de realizar a prisão do índio José Manoel "por constar que o mesmo estava ali praticando atos de superstição - cantando de cabaça”. Assim, nesta mesma noite, quatro soldados destacados na aldeia, se dirigiram até o dito engenho e conduzidos pelo professor de $1^{\mathrm{a}}$ Letras local realizaram a prisão do mencionado índio "sem consentir que ele se despisse dos enfeites com que se achasse". De fato, as principais acusações de que trata o documento são relativas, justamente, aos claros excessos e à violência do desdobramento dos acontecimentos. Depois de prenderem e darem umas primeiras “ pranchadas" no índio, a escolta o conduziu amarrado à presença de frei Ângelo que, por sua vez, também o "recebeu a bastonadas, e por ser alta noite mandou ligá-lo com cordas ao cruzeiro da Igreja, onde permaneceu até o outro dia". Na manhã do dia seguinte, após o término da missa, frei Ângelo, seguramente para dar o exemplo aos demais presentes, "fê-lo desatar e obrigou-o escoltado por duas praças a percorrer a Aldeia a tom de caixa, depois de que mandou castigá-lo corporalmente com 30 chibatadas".

3 Tais ocorrências, talvez, pudessem ter tomado outros rumos e terem sido silenciadas pelas autoridades do aldeamento se se tratasse de atos cometidos contra índio(a)s anônimo(a)s radicado(a)s na aldeia dirigida por frei Ângelo. No entanto, no caso aqui em pauta, se delineia justamente outro tipo de relação que se definia pela afinidade que certos índios mantinham com outros setores da sociedade local e que escapavam, desta forma, do controle mais imediato das autoridades dos aldeamentos indígenas oficiais, conforme previa a legislação indigenista da época (decreto 426 de 1845). o desenlace dos acontecimentos parece ter sido definido justamente pela relação que o índio castigado tinha com pessoas de fora da órbita missionária. 0 índio José Manoel, torturado por frei Ângelo, não estava sob sua jurisdição tutelar direta, por ser morador da Aldeia de Miranda. Ele estava, sobretudo, vinculado ao engenho Recreio onde trabalhava como camarada do dono, o Capitão José Manoel de Carvalho ${ }^{1}$, provavelmente, um personagem influente na política local da freguesia de Albuquerque.

4 A evolução dos acontecimentos, que pode ser claramente retraçada a partir de outros documentos existentes sobre o expediente, culminou na remoção de frei Ângelo da direção da Aldeia de Nossa Senhora do Bom Conselho. Diante da gravidade das acusações feitas contra o missionário, que incluía também denuncia de atos de "torpeza" e " imoralidade", frei Ângelo foi rapidamente transferido, em setembro de 1863, à recémcriada Colônia Militar de Dourados para dar início a um novo aldeamento indígena entre os Kaiowá e Guarani da região. Isso demonstrando que a presidência da província de Mato Grosso buscou agiu com rapidez e diplomacia. Não fosse o triste e anedótico fim de frei Ângelo, assassinado durante a Guerra da Tríplice Aliança (1864-1870) depois de cair prisioneiro das tropas de Solano Lopes, sua transferência à Colônia Militar de Dourados revelaria um acordo que nunca colocou em dúvida a ação civilizatória do missionário entre os índios da província. Assim, mais do que se atardar sobre seu lamentável fim, o que deve ser registrado a partir deste documento, é justamente o fato de que a violência como prática civilizatória sempre foi exercida dentro dos aldeamentos indígenas do 
século XIX, apesar dos princípios "brandos" ditados pela nova política indigenista do Brasil independente. Se frei Ângelo foi afastado do estabelecimento que dirigia, isso não significa que sua atuação como missionário, em algum momento, tenha sido posta em dúvida. Sua transferência revela, antes de tudo, que na equação política entre as forças locais, o dono do engenho Recreio teve vantagem em relação a frei Ângelo de Caramonico.

\section{Transcripción} no intuito de atemorizá-lo, e o conduziram amarrado à presença de Frei Ângelo, que o recebeu a bastonadas, e por ser alta noite mandou ligá-lo com cordas ao cruzeiro da Igreja, onde permaneceu até o outro dia pela manhã, quando Frei Ângelo fê-lo desatar, e obrigou-o escoltado por duas praças a percorrer a Aldeia a tom de caixa, depois de que mandou castigá-lo corporalmente com 30 chibatadas, que produziram no índio alguns ferimentos, e recolhê-lo à prisão. Finalmente que o castigo foi infligido pelos três soldados da escolta com assistência de Frei Ângelo, que remunerou espontaneamente a cada um destes com $2 \$ 000$ reis, e ao anspeçada com $5 \$ 000$ réis.

11 E para comprovar o $2^{\circ}$ facto juntou cópia de seu ofício de requisição a Frei Ângelo do índio seviciado que se achava preso na Aldeia, e certidão em original do Escrivão do Juízo, que 
portou por fé ter entregue dito ofício, e que Frei Ângelo apenas respondeu-lhe verbalmente que o havia de contestar.

O chefe da Polícia em data de 6 de Setembro transmitiu todos estes papéis ao $\mathrm{Ex}^{\mathrm{mo}}$. Snr. Conselheiro Presidente da Província ${ }^{6}$, solicitando providências, para que não ficassem impunes fatos de tanta gravidade.

13 A 13 do mesmo mês de Setembro José Joaquim de Sousa Franco e seu sócio Cap. Manoel José de Carvalho levaram à presença da Presidência uma queixa contra Frei Ângelo pelo primeiro fato supra relatado, acrescentando ao que se deixa substanciado haverem deposto as testemunhas, que o índio em questão pertence à Aldeia de Miranda, com cujo Diretor $^{7}$ o segundo queixoso havia contratado seus serviços e, por conseguinte que sobre ele nenhuma ingerência tem Frei Ângelo.

14 Para comprovar sua intenção os queixosos juntaram sob no 2, 3 e 4 a justificação em original de que a cima se fala, e dois papéis do contrato a que se referem, estando um deles com o visto do Diretor dos índios aldeados em Miranda, Frei Mariano de Bagnaia. Juntaram mais sob no 1 outra justificação produzida em abril de 1860 o requerimento de João Manoel de Castro, da qual consta alguns atos de imoralidade com os índios que se arguem a Frei Ângelo, e que este tem por costume seviciá-los e aos índios com palmatoadas, e prendê-los por tempo indeterminado; sob $\mathrm{n}^{\mathrm{0}} 5$ certidão de um ofício de Frei Ângelo ao Subdelegado de Albuquerque, em que dá a razão, pela qual deixou entregar o índio ao Cap. Manoel José [de Carvalho], bem como o que lhe induziu a mandar prendêlo; e sob no 6 um requerimento, em que se pediu certidão, que foi denegada, do Conselho de Investigação que se procedeu contra o soldado do Corpo de Artilharia da Província João Roiz Vereda por desobediência a Frei Ângelo.

16 Mandado ouvir o acusado por intermédio do Diretor Geral dos Índios, aquele respondeu em data de 10 de Outubro dizendo, que tendo chegado a seu conhecimento que a 9 de Agosto o índio Manoel José se achava praticando a meia légua de distância da aldeia no sítio do segundo queixoso um desses atos que soe sempre fazer reaparecer nos índios a superstição e a selvageria, ordenava ao anspeçada Comandante do Destacamento, que com as praças que julgasse conveniente se dirigisse a dito sítio, e depois de entregar a seu proprietário um bilhete, em que ele Frei Ângelo lhe pedia seu apoio, prendesse e conduzisse à sua presença o referido índio, o que poucas horas depois aconteceu, mas que com a chegada do preso, vendo que o anspeçada excedera suas ordens trazendo-o amarrado, ele Frei Ângelo observou-lhe que para tanto não o tinha autorizado, e desatando imediatamente o paciente, o conduziu ao cruzeiro da Igreja, e deu-lhe para castigo ficar ali de joelhos até depois da Missa, que teve lugar dali poucas horas.

Que a 12 daquele mês de Agosto recebeu um ofício do Subdelegado de Polícia do Distrito, a que não deu resposta por achar-se incomodado em sua saúde; mas que sendo-lhe entregue no dia seguinte um outro ofício, e a 15 um terceiro da mesma Autoridade, imediatamente respondera a ambos.

Impugnou a justificação em que se basearam o Subdelegado e os queixosos ponderando, que não se tinha deferido juramento as testemunhas, que não leu-se lhes seus depoimentos, que elas não foram inqueridas pelo Subdelegado, e sim por José de Sousa Brandão, em cuja venda teve lugar dita justificação, concluindo de tais circunstâncias, que o Subdelegado apenas assinou-as; tanto mais, diz-se, quanto o mesmo se achava em sua roça no dia em que a justificação se fazia na Povoação; e finalmente que confrontando-se a letra dos três ofícios do Subdelegado com a de uma carta do Cap. Manoel José [de 
Carvalho], que juntou, via-se evidentemente serem ambas de um mesmo autor, e não só por isto, como por ser aquele afilhado deste, afirmava, que o Subdelegado era pessoa do Cap. Manoel José [de Carvalho].

19 Em apoio de seu alegado juntou, a saber; sob no 1,2 e 3 os três ofícios do Subdelegado e suas duas respostas a este e por semelhantes peças oficiais ficou plenamente demonstrado a veracidade não só da requisição por parte da Autoridade Policial do índio seviciado para nele proceder-se a corpo e delito, como da recusa de Frei Ângelo em satisfazê-la, o que constitui o segundo ponto da acusação contra este (art. 154 do Código Criminal); sob no 5 uma carta do Professor de $1^{a}$ Letras da Aldeia que declara ter sido ele quem escreveu uma das respostas de Frei Ângelo ao Subdelegado; sob no 6 uma justificação prestada em outubro do ano passado perante o Juiz de Paz de Albuquerque, Marcelino Pereira Mendes, o requerimento de Frei Ângelo no qual as testemunhas depuseram que foram elas que juraram na justificação do Cap. Manoel José [de Carvalho], que esta teve lugar na venda de José de Sousa Brandão por quem foram inqueridos, e que não ouviram ler seus depoimentos; sob no 7 uma carta do Cap. Manoel José [de Carvalho] e a competente resposta de Frei Ângelo acerca do índio que se trata; sob no 8 uma outra carta do Cap. Manoel José [de Carvalho] escrita em 1861 respondendo a diversos quesitos que lhe foram propostos por Frei Ângelo sobre coisas alheias da questão; e sob no 9 uma carta de Marcolino Barbosa, que em resposta a Frei Ângelo declara que esse apenas dera ordem para prisão do índio pelo motivo supra exposto, porem não para amarrá-lo e espancá-lo, e que chegando o preso na Aldeia pelas 12 horas da noite de 9 de Agosto Frei Ângelo estranhou que a escolta o tivesse amarrado, e desatando-o conduziu dito preso ao Cruzeiro, onde pô-lo de joelhos até o dia seguinte depois da Missa.

Vê-se, portanto, que a respeito do primeiro fato e suas circunstâncias Frei Ângelo apenas negou o ter dado ordem à escolta para amarrar o índio; confessou, porém, que o mandara prender de noite dentro do estabelecimento do Cap. Manoel José [de Carvalho] e que o conservara de joelhos ao relento desde 12 horas da noite até o dia seguinte depois da Missa; e nada disse quanto às bastonadas e chibatadas, quanto à violência de fazer o índio percorrer a Aldeia a tom de caixa, quanto ao reprovado costume de castigar os índios e índias com palmatoadas; e finalmente quanto aos atos imorais que se lhe imputam; ocupando-se no final de sua resposta de acusar ao Cap. Manoel José [de Carvalho] como infrator do art. $2^{\circ} \$ 24$ do Decreto de 24 de Julho de 1845 (deve ser art. $1^{\circ}$, e não $2^{\circ}$, porque este art. não tem $\$ 24)^{8}$, que proíbe a introdução na Aldeia de bebidas espirituosas sob pena de expulsão dos introdutores.

21 Por ocasião da ida do Chefe de Polícia ao Baixo Paraguay em diligência do serviço público a Presidência julgou conveniente recomendar-lhe, que se dirigisse à Aldeia do Bom Conselho, a fim de averiguar os fundamentos das acusações supra feitas a Frei Ângelo, e dar sobre elas uma informação que o habilitasse a tomar as medidas que fossem mais justas ou necessárias: pelo que este magistrado, tendo inquirido de novo três testemunhas da justificação do Cap. Manoel José [de Carvalho] que confirmaram tudo quanto haviam nela deposto, e interrogado a Marcolino Barbosa que residira na Aldeia como mestre de alfaiates, bem como o grande número de pessoas, inclusive índios, que todos se pronunciaram no sentido das acusações; e, além disto, tendo em vista a resposta de Frei Ângelo e os documentos apresentados de uma e outra parte, em seu relatório de 31 de Dezembro do ano transato à Presidência considerou exuberantemente provadas tais acusações e informando acerca do estado da Aldeia declara que encontrou em completa decadência, com quase metade dos índios que anteriormente tinha, pela maior parte 
mulheres e meninos que vivem em grande miséria alimentando-se quase exclusivamente de frutos silvestres, e no maior desgosto para com Frei Ângelo que queixam-se eles, os maltratos com palmatoadas e com prisões injustas e excessivas, tira os filhos menores do poder de suas mães; apropria-se de alguns objetos que lhes pertencem, obriga-os com castigos a trabalhar para particulares que não lhes remuneram e serve-se das índias para fins imorais e torpes.

Pelo que respeita à introdução de bebidas espirituosas informa o Chefe de Polícia, fundado nos documentos que apresentou, ser real essa introdução na Aldeia, mas que era operada não pelo Cap. Manoel José [de Carvalho], e sim pelos índios que a vão comprar em seu estabelecimento, pelo próprio Frei Ângelo, pelo ex-mestre de alfaiate Marcolino Barbosa e pelo Professor de $1^{\mathrm{a}}$ Letras José Gomes Maciel, que também o mandam comprar em dito estabelecimento.

Nos dois relatórios de Frei Ângelo que o Diretor Geral dos Índios transmitiu à Presidência, apenas se encontram com referência à questão, a saber: huma inexatidão, quando se diz no dia $1^{\circ}$ de Janeiro, que depois da visita do Chefe de Polícia à Aldeia foi calculadamente espalhado ou por este, ou pelas pessoas de sua comitiva, o boato de que ele, Frei Ângelo, tinha de seguir acorrentado para esta Cidade, o que é uma calúnia revoltante; e a confissão feita pelo próprio Frei Ângelo no dia 22 de Março de achar-se ele desmoralizado como Diretor dos Índios.

No ofício de 6 de Março do corrente ano, com que o $1^{\circ}$ Suplente do Subdelegado de Albuquerque passou o exercício para o proprietário, e que o Chefe de Polícia levou à presença da Presidência em data de 9 de Junho com os documentos que o acompanharam, aquela autoridade policial dá como razão para não continuar na serventia os embaraços e tropeços que por parte de Frei Ângelo tem encontrado na administração da justiça, vendo-se por conseguinte na impossibilidade de atender e providenciar sobre os clamores dos índios, que não encontrando remédio a seus males, fogem a crueldade de seu Diretor abandonando a aldeia e mudando-se para Corumbá.

Eis a exposição resumida dos negócios do Bom Conselho, da qual vê-se que se acham comprovados fatos da maior gravidade contra Frei Ângelo, os quais reclamam prontas providências.

Em ofício dirigido à Presidência em data de 10 de Novembro do ano próximo passado o Diretor Geral dos Índios, remetendo o ofício original e documentos que lhe apresentou o Diretor da Aldeia do Bom Conselho, Frei Ângelo de Caramonico, em resposta às acusações contra ele dirigidas pelo Subdelegado de Polícia de Albuquerque, cujos papéis devolve à mesma Presidência, informa que aquele Diretor defende-se cabalmente das arguições que lhe fez o Subdelegado, e que, no seu entender, ele procedeu de conformidade com o Regulamento de 24 de Julho de 1845, empregando os meios ao seu alcance para reprimir os abusos que se pretendia introduzir na Aldeia sob sua direção.

Que fundado em informações fidedignas, ponderava que naquela localidade tramava-se contra o referido Diretor, por se opor aos manejos que tinham por fim locupletar certos indivíduos com os serviços dos Índios, sendo para isso necessário lançarem mão de todos os meios para desgostarem a esse Missionário até conseguirem a sua retirada da mesma Aldeia.

28 Em outro ofício datado de 24 de Abril último o Diretor Geral dos Índios, depois de dar minuciosa conta do estado da Aldeia do Bom Conselho, passa a emitir sua opinião sobre a extinção dela, dizendo que ainda não acha oportuna esta medida, por não estarem os 
respectivos Índios preparados para se confundirem na massa da população podendo neste caso voltarem aos seus antigos costumes bárbaros deste que não tenham quem os prive, $\mathrm{o}$ que só se consegue por meio do aldeamento; e também porque semelhante extinção inutilizaria tantos benefícios materiais que com não pequeno dispêndio tem-se feito na referida Aldeia.

\section{NOTAS}

1. Nota-se que o índio preso quando batizado recebeu o mesmo nome -José Manoel-que seu patrão.

2. Ano de 1862.

3. Traslado: transcrição de um texto original.

4. Graduação militar entre marinheiro e soldado.

5. Estabelecimento destinado à moagem da cana para o fabrico de açúcar, aguardente, etc.

6. Na ocasião o Conselheiro Alexandre Manoel Albino Carvalho

7. Frei Mariano de Bagnaia

8. $O$ referido Art. $2^{\circ} \$ 24$ do decreto 426 de 1845 diz o seguinte: Indagar se nas Aldeias, e seus distritos, moram pessoas de caráter rixoso, e de maus costumes, ou que introduzam bebidas espirituosas, ou que tenham enganado aos Índios com lesão enorme; e fazê-las expulsar até cinco léguas fora dos limites do distrito.

\section{RESÚMENES}

El documento que aquí se publica consiste en una serie de acusaciones de supuestos actos de violencia que el misionero capuchino Fray Ângelo de Caramonico, entonces director del asentamiento de "Nossa Senhora do Bom Conselho" en Mato Grosso do Sul, Brasil, habría cometido contra el indio Manoel José en el año de 1862. A pesar de no estar datado ni firmado, no es difícil contextualizar este documento a partir de otros existentes como este en el Arquivo Público do Estado de Mato Grosso (APMT). La reconstrucción del contexto histórico de producción de este documento resulta de interés para la comprensión de las lógicas que dan sentido a las diferentes posiciones presentadas por los actores involucrados en ese "juego de acusaciones".

The document published here is a series of accusations of alleged violence that the missionary Fray Angelo of Caramonico, then director of the Indian village of "Nossa Senhora do Bom Conselho" in Mato Grosso do Sul, Brazil, had committed against Indian Manoel José in 1862. Despite not being dated or signed, it is not difficult to contextualize this document with others like this one existing in the "Arquivo Público do Mato Grosso" (APMT). The reconstruction of the 
historical context in which this document was produced is relevant to understand the logic that gives meaning to the various positions presented by the actors of this "blaming game".

ÍNDICE

Keywords: Indians villages, Mato Grosso do Sul, Capuchin missionaries, Fray Ângelo de Caramonico.

Palabras claves: Asentamientos indígenas, Mato Grosso do Sul, Misioneros capuchinos, Fray Ângelo de Caramonico.

\section{AUTOR}

\section{PABLO ANTUNHA BARBOSA}

Museu Nacional da Universidade Federal do Rio de Janeiro, Brasil y Escuela de Altos Estudios Sociales, Francia. Correo electrónico: pablo.antunha.barbosa@gmail.com 